\title{
THE ROLE OF PERSONALITY TRAITS IN SEVERITY OF MENIERE'S DISEASE
}

A.B.Medeiros' ${ }^{1}$, F. Correia',3, L. Castelhano 2,3 , P. Cavilhas 2,3, F. Gonçalves' 1

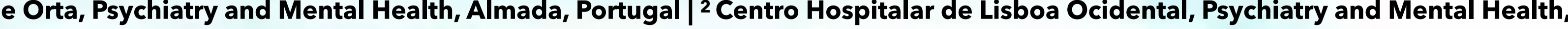
Lisboa, Portugal | ${ }^{3}$ Nova Medical School, Faculdade de Ciências Médicas - Universidade NOVA de Lisboa, Lisboa, Portugal

\section{objectives and Background}

Meniere"s Disease (MD):

Chronic disorder of the inner ear;

Recurrent spontaneous crisis: $\checkmark$ Severe vertigo;

Clinical course - variable $\checkmark$ Hearing loss;

$\checkmark$ Tinnitus.

- Triggers for the crisis - multiple factors

Including psychological ones

Correlation vertigo/anxiety - is known

But

Role of anxiely and personality traits in MD course???

Aim:

- To study the influence of personality traits and anxiety spectrum psychopathology in the course of Menière's disease (MD).

\section{Material and Methods}

$\mathrm{N}=34$ | Diagnosis of definite MD (2016 consensus)

\begin{tabular}{|c|c|}
\hline $\begin{array}{l}\text { Characterization } \\
\text { of course of disease }\end{array}$ & $\begin{array}{l}\text { Description of personality trait } \\
\text { and anxiety states }\end{array}$ \\
\hline $\begin{array}{l}\text { Face to face interview } \\
\text { Dizziness Handicap } \\
\text { Inventory (DHI) OR1 } \\
\text { Visual Analogic Scale for } \\
\text { vertigo (VAS) QR2 }\end{array}$ & $\begin{array}{l}\text { Face to face psychiatric } \\
\text { interview (DSM-5 criteria) } \\
\text { Neo Personality Inventory } \\
\text { Reviewed (NEO-PI-R) OR3 } \\
\text { State Trait Anxiety Inventory } \\
\text { (STAI) OR4 }\end{array}$ \\
\hline
\end{tabular}
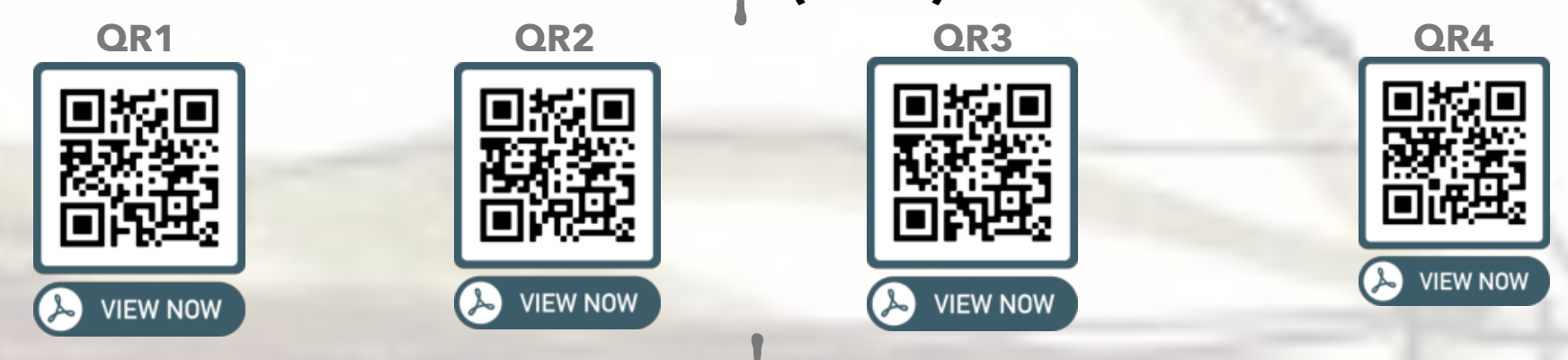

SPSS - Univariable and multivariable analysis

Results and Conclusions N=34 | 50\% Female; 50\% Male | Pathological personality traits: $81.3 \%$
Mood or anxiety disorders: $34.4 \%$ | Average VAS during crisis: 8.8 Average VAS out of crisis: 2.9 | Average STAI Y-1: 41.2 |Average STAI Y-2: 42.5

Average results of NEO-PI-R

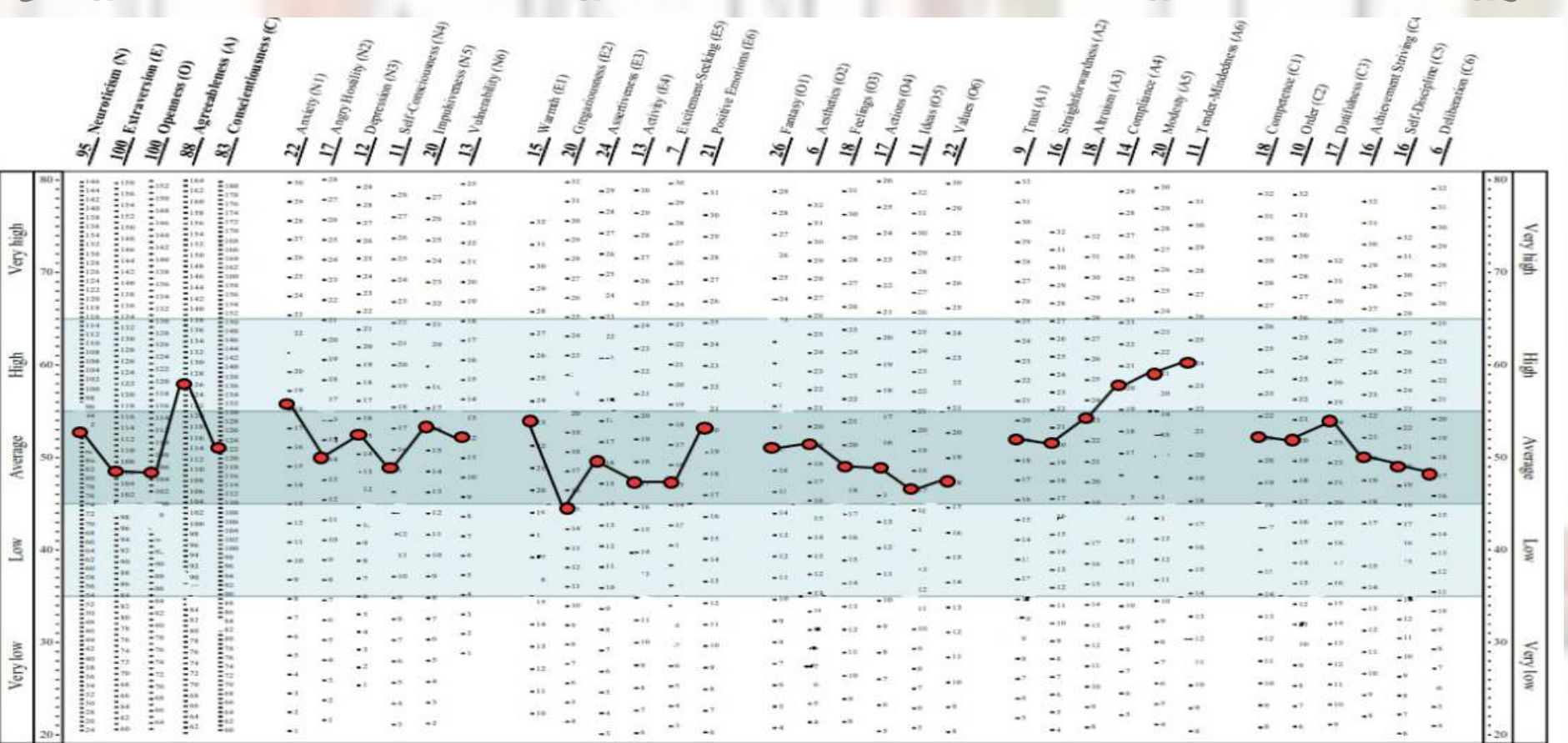

Crisis Frequency
Crisis Severity

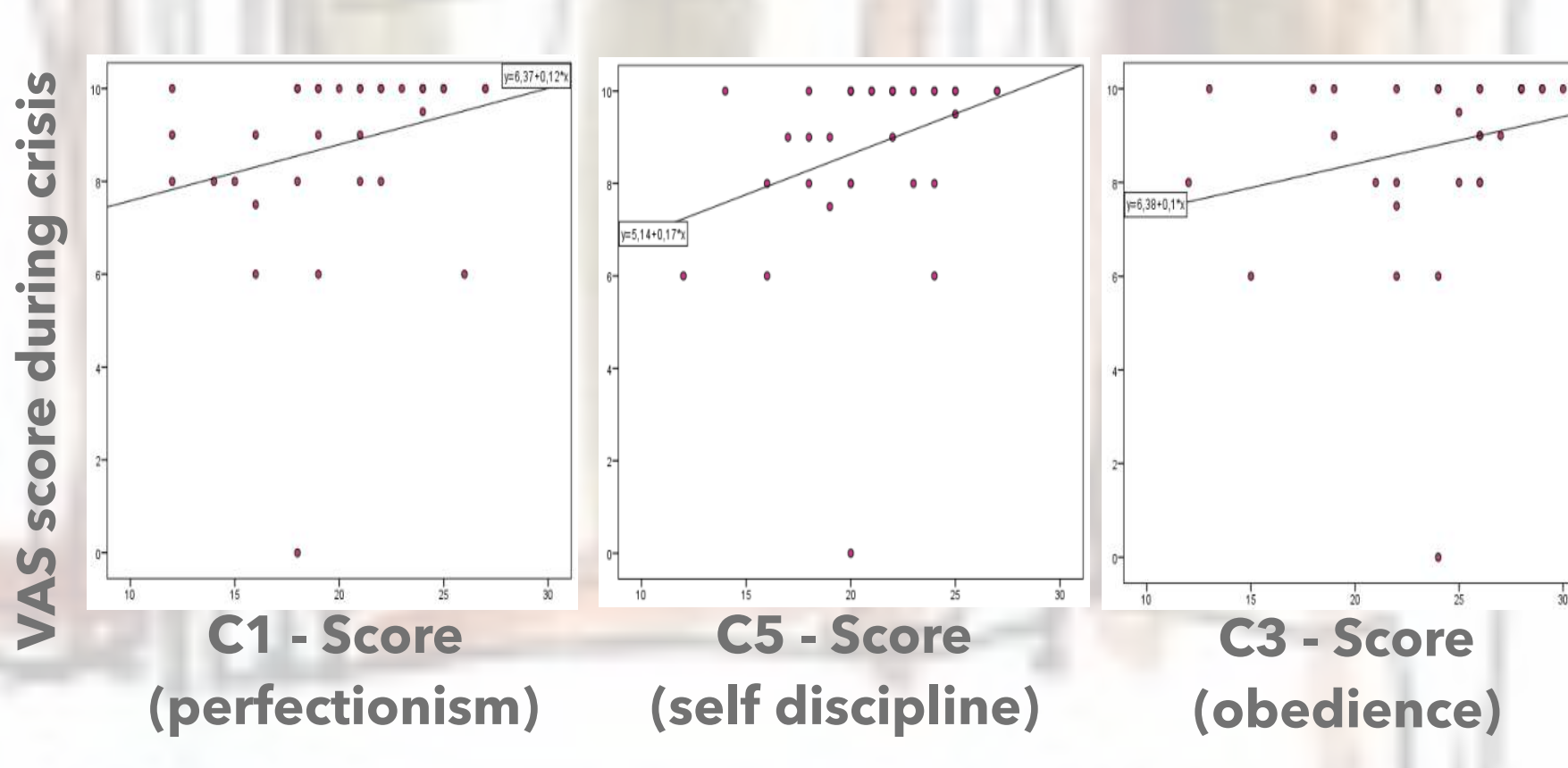

Life Quality

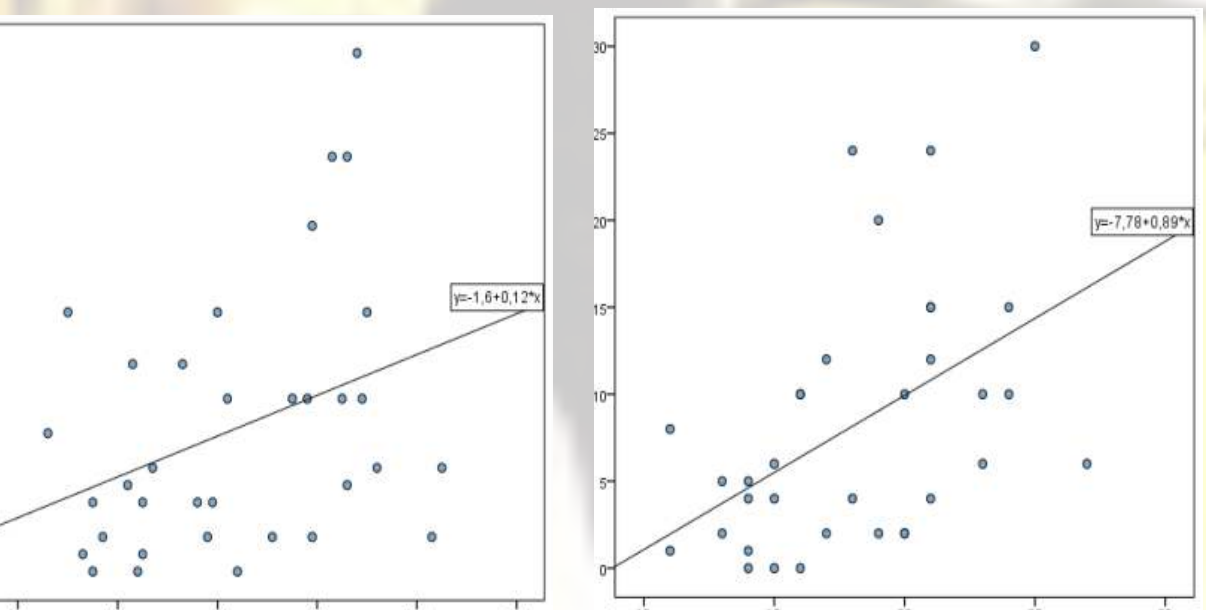

STAI - Score

N1 - Score

(Neuroticism)

N1 - Score

(Neuroticism)
A1 - Score

(Confidence)

- Statistically significant positive correlations $(p<0,05)$ :

- between crisis rate, crisis severity, quality of life and the existence of mood or anxiety disorders and also anxiely-related personality traits.

The relationship between anxiety states and MD may be bidirectional. However, the role of personality traits in the course of this disease is an indicative of a psychosomatic modulator for the disorder.

These results support the relevance of prospecting adjuvant psychological and psychiatric approaches to these patients, like cognitive- behavior psychotherapy or psychopharmacology strategies. 